\title{
Attitudes of dental patients towards participation in research
}

\author{
S. Al-Amad, ${ }^{1}$ M. Awad ${ }^{1}$ and H. Silverman ${ }^{2}$
}

$$
\text { مو اقف مرضى طاني العمد، منال عوض، هنري الأسنان تجاه المساهمة في البحوث }
$$

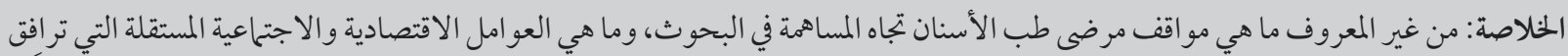

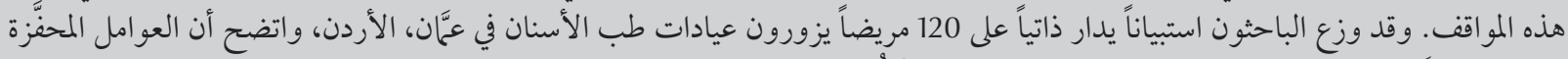

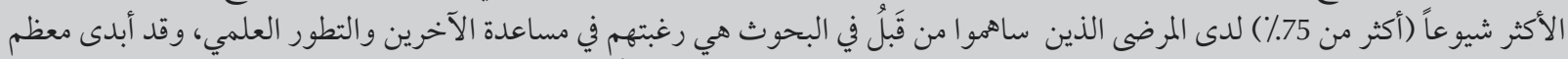

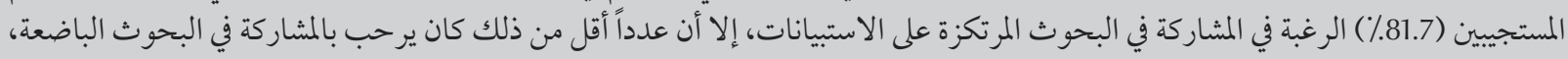

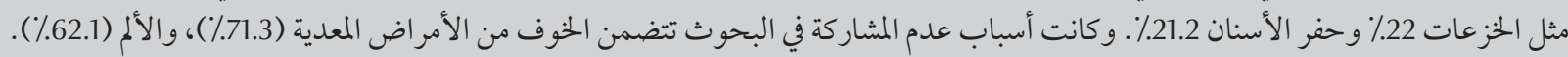

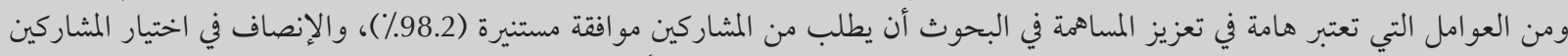

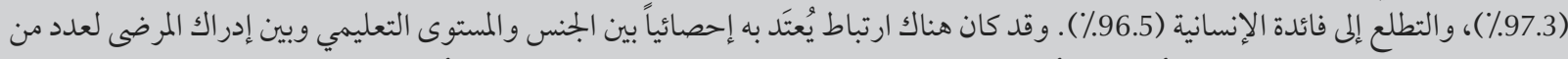

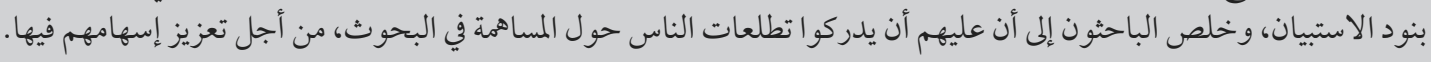

ABSTRACT The attitudes of dental patients towards participation in research and the independent socioeconomic factors associated with these attitudes are not known. A self-administered questionnaire was distributed to 120 patients attending dental clinics in Amman, Jordan. For patients who had previously participated in research ( $n=$ 28 ), motivating factors for most (> 75\%) included a desire to help others and to advance science. Most respondents (81.7\%) showed interest in participating in questionnaire-based research, but fewer would participate in invasive research, e.g. biopsies (22.0\%) and drilling teeth (21.2\%). Reasons given for not participating in research included fear of infectious diseases $(71.3 \%)$ and pain (62.1\%). Factors considered important in enhancing research participation included being asked to give informed consent (98.2\%), fairness in selection of participants (97.3\%) and the prospect of humanitarian benefit (96.5\%). Sex and education level were significantly associated with patients' perceptions for several of items. To enhance recruitment, researchers should be aware of people's perspectives regarding participation in research.

\begin{abstract}
Attitudes des patients dentaires vis-à-vis de la participation à la recherche
RÉSUMÉ Les attitudes des patients dentaires vis-à-vis de la participation à la recherche et les facteurs socioéconomiques indépendants associés à ces attitudes ne sont pas connus. Un autoquestionnaire a été distribué à 120 patients consultant dans des centres de soins dentaires à Amman (Jordanie). Parmi les facteurs de motivation pour la majorité (> $75 \%$ ) des patients ayant déjà participé à une étude de recherche $(n=28)$, on peut citer le désir d'aider autrui et de faire avancer la science. La plupart des répondants (81,7\%) exprimaient un intérêt pour la participation à une recherche menée à partir d'un questionnaire, mais ils étaient moins nombreux à être volontaires pour participer à une recherche invasive, telles que des biopsies (22,0 \%) et le forage de dents (21,2 \%). La peur des maladies infectieuses (71,3\%) et la douleur (62,1\%) étaient les raisons citées pour ne pas participer à une recherche. Les facteurs considérés comme importants pour améliorer la participation à la recherche comprenaient l'obtention d'un consentement éclairé (98,2 \%), l'équité dans la sélection des participants (97,3\%) et la perspective d'un avantage humanitaire (96,5\%). Le sexe et le niveau d'études étaient fortement associés à la perception des patients pour plusieurs items. Afin d'intensifier le recrutement, les chercheurs devraient être informés des points de vue des patients au sujet de la participation à la recherche.
\end{abstract}

${ }^{7}$ College of Dentistry, University of Sharjah, Sharjah, United Arab Emirates (Correspondence to S. Al-Amad: salamad@sharjah.ac.ae). ${ }^{2}$ University of Maryland School of Medicine, Baltimore, Maryland, United States of America.

Received: 12/02/13; accepted: 21/05/13 


\section{Introduction}

Health research has been undergoing huge leaps during the past decade, particularly in the developing world [1]. Research in Jordan is growing, but at a slower pace compared with the other countries in the region such as Turkey, Islamic Republic of Iran and Egypt $[2,3]$. Research in health usually involves human participation. This involvement often carries risks, which can be minimized by adhering to fundamental ethical principles that guarantee the protection of the research participants $[4,5]$. To enhance the safety and the ethical conduct of research, Jordan issued the Clinical Research Law in 2001, which mandated the review of research by an ethics committee and specified penalties against researchers and research institutes for not complying with its ethical standards [6].

An important factor for successful research includes high levels of patient recruitment. Knowledge regarding the understandings, perspectives and concerns of individuals regarding their involvement in medical research are important for improving recruitment efforts, enriching the informed consent process and enhancing the overall trust between investigators and the public. Several qualitative studies have been performed, including those from the United States, Denmark, Australia and Japan, to elicit the views of patients regarding medical research [7-11]. Such results, however, might not be generalizable to developing countries which incorporate different ethnic groups, religions, cultures, economic and political backgrounds. Accordingly, studies on patients about medical research have been performed in some developing countries, including those from countries in the Middle East [12-14]. It is also not known whether such results can be extended to research in dentistry. The field of dentistry involves research which investigates causes and treatment of oral and dental diseases, and dental research is subjected to the same ethical standards as in medical research [15].

The aims of the current study were to explore the attitudes of individuals regarding their decision to participate in dental research and to determine the socioeconomic factors that might be associated with these responses. We expect that information obtained from this study would be helpful to individuals involved with research in Jordan as well as those involved with research in developing countries in general.

\section{Methods}

\section{Study design and sampling}

We conducted a cross-sectional survey on patients attending 1 public and 4 private dental clinics in different parts of Amman, the capital city of Jordan. Jordan has a population of approximately 6.35 million. The Jordanian economy is modest with a gross domestic product (GDP) per capita of approximate US\$ 5000 and its health-care expenditure represents $10.5 \%$ of the country's GDP [16].

In order to approach patients of diverse socioeconomic classes, dental clinics were selected from different geographical locations in western Amman (prosperous) and eastern Amman (less prosperous). Inclusion criteria were dental patients who were 18 years and above, and literate. Dental receptionists were given an orientation session on how to approach patients and invite them to participate in the study. Patients were given an information sheet that provided details about the survey and contact details of the principal investigator. Receptionists were instructed to explain the nature of this research, why the patient was chosen, and their right to refuse participation or to withdraw from this survey without their decision affecting the quality of their treatment.

This study was approved by the research ethics committee of the Jordanian Ministry of Health and of the
University of Maryland School of Medicine.

\section{Data collection}

We developed a self-administrated questionnaire in the Arabic language. The questionnaire consisted of $6 \mathrm{sec}-$ tions. The 1st section enquired about sociodemographic characteristics: age, sex, level of education, income and type of clinic attended (public versus private). Due to our small sample size, we collapsed the different levels in some of the categories; for example, the educational levels were divided into school (for those with incomplete or complete school education) and college/ university (for those who were enrolled or completed a community college or university degree programme). The monthly income in Jordanian dinars (JD) was divided into 2 categories: JD < 500 and $\geq 500$.

The 2 nd section enquired about respondents' prior participation in medical and dental research and their motives for enrolment in the research. Responses were strong, possible, weak and inapplicable. The 3rd section asked respondents about their willingness to participate in various types of dental research. Possible responses were in the format of a 5-point Likert scale that ranged from 1 to 5 ( 1 = certainly will participate; $2=$ maybe will participate; 3 = uncertain; 4 = will not participate; and $5=$ certainly will not participate). The 4th section enquired about factors that would discourage participation in research. Possible responses were in the format of a 5-point Likert scale that ranged from 1 to 5 ( $1=$ very strong reason; $2=$ strong reason; $3=$ possible reason; $4=$ weak reason; and $5=$ inapplicable). The 5 th section covered questions about the factors that would encourage research participation. Possible responses included very important, important, not important, and inapplicable. The 6th section enquired about participants' level of comfort with participating in research that involved 
randomization. Responses included: very comfortable, somewhat comfortable, not comfortable, not comfortable at all, and indifferent.

We pilot tested our survey with 10 individuals from various educational and socioeconomic backgrounds and subsequently made some changes to the survey's language and style to enhance its comprehensibility. Cronbach a was 0.89 which indicates a high reliability of the questionnaire.

\section{Statistical analysis}

PASW for Windows, version 18 (SPSS Inc.) was used for statistical analysis. For the purposes of analysis, we collapsed the first 2 affirmative categories of each question set, for example strong and possible (2nd section); certainly will participate and maybe will participate (3rd section); very strong reason and strong reason (4th section); very important and important (5th section); and very comfortable and somewhat comfortable (6th section). Data analysis included $t$-tests for continuous variables and chi-squared tests for categorical variables. Responses in the various sections were correlated with sex, education and income. $P$-value was significant if $<0.05$.

\section{Results}

A total of 120 respondents participated in this survey. Table 1 shows the demographic characteristics of the respondents. The majority of the sample were women $(60.8 \%)$, held a community college or university degree ( $81.7 \%)$ and had a monthly income of $\geq$ JD 500 (63.3\%).

Figure 1 shows the respondents' motives for participating in research among those who had participated in dental $(n=9)$ or medical research $(n=19)$. More than $75 \%$ of the respondents stated they had participated in dental or medical research in order to help others, to help advance

\begin{tabular}{|c|c|c|}
\hline Variable & No. & $\%^{\mathrm{a}}$ \\
\hline \multicolumn{3}{|l|}{ Sex } \\
\hline Men & 47 & 39.2 \\
\hline Women & 73 & 60.8 \\
\hline \multicolumn{3}{|l|}{ Educational level } \\
\hline School, not completed & 1 & 0.8 \\
\hline School, completed & 21 & 17.5 \\
\hline Community college & 15 & 12.5 \\
\hline University & 83 & 69.2 \\
\hline \multicolumn{3}{|l|}{ Income (JD) } \\
\hline$<200$ & 7 & 5.8 \\
\hline $200-500$ & 37 & 30.8 \\
\hline $501-1000$ & 37 & 30.8 \\
\hline$>1000$ & 39 & 32.5 \\
\hline \multicolumn{3}{|l|}{ Employment } \\
\hline Student & 16 & 13.3 \\
\hline Vocational & 56 & 46.7 \\
\hline Academic & 16 & 13.3 \\
\hline Unemployed & 28 & 23.3 \\
\hline Retired & 4 & 3.3 \\
\hline \multicolumn{3}{|l|}{ Clinic attended } \\
\hline Private & 93 & 77.5 \\
\hline Public & 27 & 22.5 \\
\hline
\end{tabular}

${ }^{a}$ Percentages do not always sum to $100 \%$ because of rounding. $J D=$ Jordanian dinars.

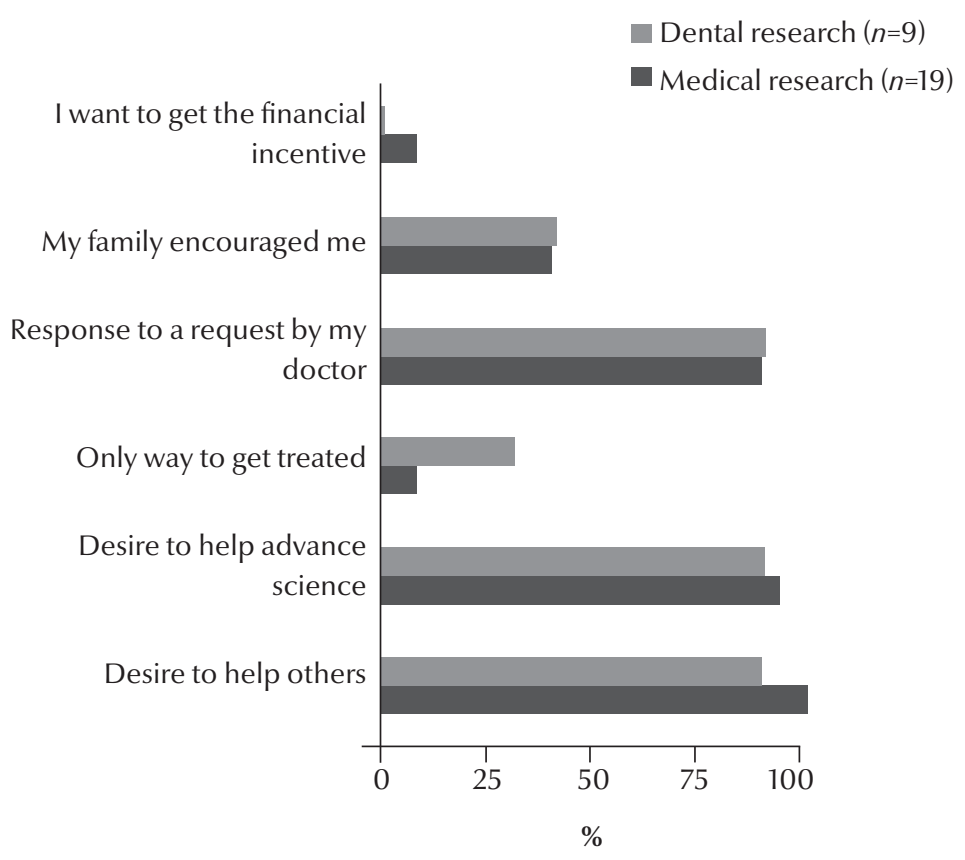

Figure 1 Motives for participation among patients who had participated previously in dental research and medical research 


\begin{tabular}{|c|c|c|c|c|c|c|c|}
\hline \multirow[t]{3}{*}{ Research intervention } & \multirow{2}{*}{$\begin{array}{l}\text { All participants } \\
\qquad(n=120)\end{array}$} & \multicolumn{2}{|c|}{ Sex } & \multicolumn{2}{|c|}{ Educational level } & \multicolumn{2}{|c|}{ Income (JD) } \\
\hline & & $\begin{array}{c}\text { Men } \\
(n=47)\end{array}$ & $\begin{array}{l}\text { Women } \\
(n=73)\end{array}$ & $\begin{array}{l}\text { School } \\
(n=22)\end{array}$ & $\begin{array}{c}\text { College/ } \\
\text { university } \\
(\boldsymbol{n}=\mathbf{9 8})\end{array}$ & $\begin{array}{l}<500 \\
(n=44)\end{array}$ & $\begin{array}{l}\geq 500 \\
(n=76)\end{array}$ \\
\hline & $\%$ & $\%$ & $\%$ & $\%$ & $\%$ & $\%$ & $\%$ \\
\hline Surveys & 81.7 & 83.7 & 80.3 & 72.2 & 83.5 & 82.1 & 81.4 \\
\hline Oral swabs & 52.8 & 57.5 & 50.0 & 50.0 & 53.3 & 50.0 & 54.3 \\
\hline Saliva collection & 51.4 & 56.1 & 48.5 & 52.6 & 51.1 & 44.7 & 54.9 \\
\hline Topical medications & 50.5 & 56.1 & 47.1 & 52.6 & 50.0 & 60.5 & 45.1 \\
\hline Restoration & 44.4 & 53.7 & 38.8 & 57.9 & 41.6 & 50.0 & 41.4 \\
\hline Biopsies & 22.0 & 24.4 & 20.6 & 21.1 & 22.2 & 18.4 & 23.9 \\
\hline Surgical procedures & 21.1 & $31.7^{* *}$ & 14.7 & $42.1^{* *}$ & 16.7 & $31.6^{*}$ & 15.5 \\
\hline
\end{tabular}

${ }^{*} P<0.05$; ${ }^{*} P<0.01$.

$J D=$ Jordanian dinars

science or in response to a request by the doctor. Opportunities to receive treatment or financial incentives were not major reasons for participating in research.

Table 2 shows the respondents' preferences for participating in types of research involving different interventions. Respondents were less likely to participate in more invasive research (e.g. biopsies and surgical procedures) compared with less invasive research (e.g. surveys). Men, those with only school education and low-income respondents were significantly more likely to participate in research involving surgical procedures compared with women and those with higher education and higher income $(P<0.01, P<$ 0.01 and $P<0.05$ respectively).

Table 3 shows the respondents' self-reported barriers to participating in dental research. Their greatest concerns were fear of acquiring an infectious disease $(71.3 \%)$ and pain (62.1\%). Women were significantly more likely than men to consider pain, dental phobia and acquiring infectious diseases as important reasons for refusing to participate in research (all $P<$ $0.05)$. College/university graduates were significantly more likely than those with only school education to refuse participation due to concerns related to toxicity of the experimented dental materials and fear of impaired chewing (both $P<0.05$ ). Income level did not affect reasons for refusal to participate.

Table 4 shows the factors that would encourage respondents to participate in research. More than 90\% of respondents rated the following as important determinants for participation: written informed consent, privacy, a benefit to humanity, medical insurance to cover research-related injury, and fairness in the selection

\begin{tabular}{|c|c|c|c|c|c|c|c|}
\hline \multirow[t]{3}{*}{ Reason for not participating } & \multirow{2}{*}{$\begin{array}{c}\text { AII } \\
\text { participants } \\
(n=120)\end{array}$} & \multicolumn{2}{|c|}{ Sex } & \multicolumn{2}{|c|}{ Educational level } & \multicolumn{2}{|c|}{ Income (JD) } \\
\hline & & $\begin{array}{c}\text { Men } \\
(n=47)\end{array}$ & $\begin{array}{c}\text { Women } \\
(n=73)\end{array}$ & $\begin{array}{l}\text { School } \\
(n=22)\end{array}$ & $\begin{array}{c}\text { College/ } \\
\text { university } \\
(n=98)\end{array}$ & $\begin{array}{l}<500 \\
(n=44)\end{array}$ & $\begin{array}{l}\geq 500 \\
(n=76)\end{array}$ \\
\hline & $\%$ & $\%$ & $\%$ & $\%$ & $\%$ & $\%$ & $\%$ \\
\hline Infectious diseases & 71.3 & 53.8 & $82.3^{*}$ & 77.3 & 69.6 & 71.1 & 71.4 \\
\hline Pain & 62.1 & 43.6 & $73.4^{*}$ & 66.7 & 61.0 & 62.2 & 62.1 \\
\hline Multiple visits & 51.5 & 41.0 & 58.1 & 59.1 & 49.4 & 52.6 & 50.8 \\
\hline Dental phobia & 50.5 & 28.2 & $64.5^{*}$ & 63.6 & 46.8 & 52.6 & 49.2 \\
\hline Impairment to appearance & 47.5 & 38.5 & 53.2 & 36.4 & 50.6 & 42.1 & 50.8 \\
\hline Fear of poison & 44.4 & 43.2 & 45.2 & 23.8 & $50.0^{*}$ & 35.1 & 50.0 \\
\hline Chewing problems & 44.4 & 47.4 & 42.6 & 22.7 & $50.6^{*}$ & 35.1 & 50.0 \\
\hline Privacy violation & 26.5 & 35.9 & 20.6 & 27.3 & 26.3 & 26.3 & 26.6 \\
\hline
\end{tabular}

${ }^{*} P<0.05$.

$J D=$ Jordanian dinars 


\begin{tabular}{|c|c|c|c|c|c|c|c|}
\hline \multirow[t]{3}{*}{ Item } & \multirow{2}{*}{$\begin{array}{c}\text { All } \\
\text { participants } \\
(n=120)\end{array}$} & \multicolumn{2}{|c|}{ Sex } & \multicolumn{2}{|c|}{ Educational level } & \multicolumn{2}{|c|}{ Income (JD) } \\
\hline & & $\begin{array}{c}\text { Men } \\
(n=47)\end{array}$ & $\begin{array}{c}\text { Women } \\
(n=73)\end{array}$ & $\begin{array}{l}\text { School } \\
(n=22)\end{array}$ & $\begin{array}{c}\text { College/ } \\
\text { university } \\
(n=98)\end{array}$ & $\begin{array}{l}<500 \\
(n=44)\end{array}$ & $\begin{array}{c}\geq 500 \\
(n=76)\end{array}$ \\
\hline & $\%$ & $\%$ & $\%$ & $\%$ & $\%$ & $\%$ & $\%$ \\
\hline Written informed consent & 98.2 & 95.2 & 100.0 & 100.0 & 97.8 & 100.0 & 97.1 \\
\hline Fairness in selection of participants & 97.3 & 97.6 & 97.1 & 90.9 & $98.9^{*}$ & 95.2 & 98.6 \\
\hline Benefit to humanity & 96.5 & 97.7 & 95.7 & 95.5 & 96.7 & 97.7 & 95.7 \\
\hline Medical insurance & 92.0 & 88.1 & 94.4 & 95.5 & 91.2 & 97.6 & 88.7 \\
\hline Privacy & 91.2 & 83.7 & $95.8^{*}$ & 90.0 & 91.3 & 93.0 & 90.1 \\
\hline Confidentiality & 88.5 & 81.0 & $93.0^{*}$ & 90.0 & 87.9 & 92.9 & 85.9 \\
\hline Review by ethics committee & 88.5 & 90.5 & 87.3 & 86.4 & 89.0 & 97.6 & $83.1^{*}$ \\
\hline Involvement of my dentist & 86.7 & 86.0 & 87.1 & 81.8 & 87.9 & 79.1 & 91.4 \\
\hline Involvement of my physician & 86.6 & 90.2 & 84.5 & 85.7 & 86.8 & 81.0 & 90.0 \\
\hline Personal benefit & 85.7 & 83.3 & 87.1 & 90.9 & 84.4 & 92.9 & 81.4 \\
\hline Compensation for damages & 75.2 & 71.4 & 77.5 & 81.8 & 73.6 & 83.3 & 70.4 \\
\hline Community benefit & 72.1 & 69.0 & 73.9 & $90.5^{*}$ & 67.8 & $82.9^{*}$ & 65.7 \\
\hline Researchers are locals & 51.8 & 55.8 & 49.3 & 76.2 & $46.2^{*}$ & $66.7^{*}$ & 42.9 \\
\hline
\end{tabular}

${ }^{*} P<0.05$.

$J D=$ Jordanian dinars.

of participants. Women were significantly more likely than men to rate confidentiality and privacy as important factors that would encourage their participation (both $P<0.05$ ). College/university graduates were significantly more likely than those with only school education to consider fairness in selection of participants as a factor in their participation $(P$ $<0.05$ ) and were less likely to consider community benefit and the locality of the researchers in deciding whether to participate (both $P<0.05$ ). Low-income participants compared with those with higher income were significantly more likely to consider community benefit, the presence of an ethics committee review and the locality of the researchers as important factors for participation (all $P<0.05$ ).

Table 5 shows the respondents' comfort level with several aspects of being enrolled in a randomized, double-blinded, controlled trial. A minority of respondents stated they would feel comfortable with not having a choice regarding the drug they would receive $(37.3 \%)$, not knowing which drug they were receiving (27.9\%) and their doctor not knowing which drug they were receiving (17.3\%). Women were significantly less likely than men to feel comfortable with not knowing which drug they were receiving $(21.4 \%$ versus $39.0 \%$; $P<0.05$ ).

\begin{tabular}{|c|c|c|c|c|c|c|c|}
\hline \multicolumn{8}{|c|}{$\begin{array}{l}\text { Table } 5 \text { Respondents' comfort level regarding aspects of being enrolled in randomized, double-blinded research: percentage } \\
\text { of respondents who would feel somewhat or very comfortable with the situation }\end{array}$} \\
\hline \multirow[t]{3}{*}{ Item } & \multirow{2}{*}{$\begin{array}{c}\text { All } \\
\text { participants } \\
(n=120)\end{array}$} & \multicolumn{2}{|c|}{ Sex } & \multicolumn{2}{|c|}{ Educational level } & \multicolumn{2}{|c|}{ Income (JD) } \\
\hline & & $\begin{array}{c}\text { Men } \\
(n=47)\end{array}$ & $\begin{array}{l}\text { Women } \\
(n=73)\end{array}$ & $\begin{array}{l}\text { School } \\
(n=22)\end{array}$ & $\begin{array}{l}\text { College/ } \\
\text { university } \\
(\boldsymbol{n}=\mathbf{9 8})\end{array}$ & $\begin{array}{l}<500 \\
(n=44)\end{array}$ & $\begin{array}{l}\geq 500 \\
(n=76)\end{array}$ \\
\hline & $\%$ & $\%$ & $\%$ & $\%$ & $\%$ & $\%$ & $\%$ \\
\hline $\begin{array}{l}\text { I will not have a choice as to which drug } \\
\text { I will receive }\end{array}$ & 37.3 & 42.5 & 34.3 & 55.0 & 33.3 & 42.9 & 33.8 \\
\hline $\begin{array}{l}\text { I will not know whether I am taking the } \\
\text { standard drug or the experimental drug }\end{array}$ & 27.9 & 39.0 & $21.4^{*}$ & 25.0 & 28.6 & 28.6 & 27.5 \\
\hline $\begin{array}{l}\text { My doctor will not know which drug I } \\
\text { will be taking }\end{array}$ & 17.3 & 25.0 & 12.9 & 25.0 & 15.6 & 19.0 & 16.2 \\
\hline
\end{tabular}




\section{Discussion}

This study revealed several important insights regarding the perspectives of Jordanian patients toward dental research, which might be applicable to individuals in other countries in the Middle East. Also, such knowledge might help sensitize investigators to the concerns held by potential participants, thus enhancing trust in the research endeavour, as well as enhancing recruitment efforts.

First, of those respondents who had previously participated in dental or medical research, the major motives for participation included a desire to help others or to advance science. Other studies have also shown that other types of patients harbour such altruistic reasons to join clinical research or continue to participate in research [17-20]. For example, Wendler et al. showed that HIV patients would participate in research to benefit others even when there was limited or no benefit to them [17]. Altruism, however, is not the sole motivating factor to participate in research, as other studies have shown that the potential for self-benefit was a reason to participate in research $[18,19]$.

Our results also showed that participating in research as the only way to get treatment was not a predominate reason among our respondents. Other studies have demonstrated that access to health care can serve as a reason to join a research study. For example, in a study that involved patients with rheumatoid arthritis, $63 \%$ of the respondents stated that easy access to free complete laboratory tests was a motivating factor [18]. The likelihood that access to treatment would be a motivating factor will probably depend on health system issues that vary from country to country, as well as other factors such as income level, geographical location, type of treatment and medical tests required by the patient. For example, in an in-depth interview study involving individuals from developing countries who were participating in international clinical trials, the opportunity to receive better medical care was a major incentive to participate in the trials [21]. As we recruited patients who were at their point of care (dental clinics), it is probably not surprising that access issues were not a motivating factor for them.

Our study also showed that the possibility of obtaining a financial incentive was not an important reason to participate in research. The issue of payments to incentivize individuals to participate in research is ethically controversial [22-24]. In one study, Halpern et al. showed that payment was more influential in a decision to participate in research among the wealthier patients [25]. In another study involving volunteers participating in phase I research (in which there is no medical benefit), money was the second most commonly cited reason (after contributing to science) to have enrolled in the research, with college graduates being 3.2 times more likely to consider financial incentives as good aspect of participation compared to those with less education [26].

Finally, more than $75 \%$ of our respondents stated that they would enrol in research in a response to a request from their doctor/dentist. Reasons to explain this observation would include perceived coercion, i.e. a concern that future access to health care would be jeopardized if one refused enrolment. Other studies have shown that a desire to maintain a good relation with their doctor or a sense of obligation to the doctor served as additional motivating factors to participate in research $[18,27]$. Future qualitative research should explore further the underlying reasons why patients would enrol in research due to a request from their doctor/dentist.

Our study also uncovered factors that could affect patients' willingness to participate in dental research. For example, participation in future research was conditional on the level of the invasiveness of the research interventions. Specifically, most respondents found studies involving surveys to be acceptable, but their willingness to participate decreased with greater degrees of perceived discomfort (e.g. oral swabs, saliva collection, topical medications) or perceived risks associated with the research (e.g. biopsies and surgical procedures). Those results are consistent with another study involving in-depth interviews of Egyptians, which also showed that an interest in participating in medical research was inversely related to participants' perceptions of the risks associated with research [12]. For example, most participants found studies involving less then minimal risk (e.g. surveys and blood sampling) to be acceptable. However, patients' willingness to participate decreased with a greater degrees of perceived risks associated with the research (e.g. endoscopy and drug trials) [12].

Our study also demonstrated that preferences for types of interventions were correlated with several demographic variables. For example, women, college/university graduates, and those with higher incomes were significantly less willing to participate in research involving surgical procedures compared with men and those with school education or lower income. Further qualitative research should explore the underlying factors that account for these differences.

One concern regarding dental research among our study patients was that approximately half of them would hesitate to enrol even in what would be considered low-risk studies (e.g. oral swaps, saliva collection and topical medications). In addition to concerns about discomfort and risks, approximately half of our respondents cited other factors that would discourage their participation in research. These included the transmission of infectious diseases, the possibility of pain, the need for multiple visits and dental phobia. 
These findings demonstrate the need for education programmes to raise awareness regarding the importance of research participation, reduce any unnecessary fears and dispel myths about clinical research.

Another factor that might hinder research participation included discomfort with certain research practices, e.g. randomization, double blinding and control groups. Indeed, many of the respondents in our study did not feel comfortable with not having a choice in the selection of the drug, not knowing which drug they would be receiving and not having their doctor know which drug they would receive. Other investigators have also uncovered discomfort and misunderstanding with research concepts among a broad range of populations [8-10,12,21,28-31]. For example, in the study by Khalil et al. many participants neither felt comfortable with nor understood the need for randomization, and many were also confused and concerned with the concept of doctors being blinded to their study drug assignment [12]. A study involving Danish patients with cancer and inflammatory bowel disease also found that many had a negative or a hesitant view of randomization and that several would have wanted to choose the treatment option themselves [8]. A focusinterview study of Japanese people also discovered that many had a feeling of repulsion towards randomization [10]. An Australian study found that many patients disliked being part of an experiment, and patients' willingness to join a clinical trial was negatively associated with uncertainty of treatment allocation [28]. A study involving oncology patients found that only one-third of the respondents would consider taking part in a trial comparing different treatments in which the treatment was selected at random by a computer [9], while other researchers found that participants' previous treatment satisfaction affected their preferences to be in a specific group in randomized clinical trials [31].

Difficulty understanding or feeling uncomfortable with the concept of randomization and blinding might be due to therapeutic misconception [31-33], whereby participants believe that they are receiving the best medical care in the context of a research study. Such a belief would make it difficult for individuals to understand why there is no choice in the selection of the drug, why they cannot know the identity of the drug and why their doctor would not know which study drug they would be receiving. Other studies have also found that patients and individuals attach a therapeutic orientation to research. For example, in an interview study involving Egyptians, many were unable to distinguish between research and medical care [34]. Studies involving patients from Western countries also revealed the presence of a therapeutic misconception $[8,9,35]$.

In addition to identifying factors that might hinder research participation, we also uncovered factors that promote participation in research. For example, the vast majority of respondents rated a written informed consent as the most important factor in deciding their participation in dental research. Other studies have also observed that potential research participants attach great importance to the concept of informed consent $[12,36,37]$. Essentially, being respected as a person by being asked to participate in research probably enhances trust in the research endeavour. Other commentators have also shown the importance of trust in enhancing research participation $[12,18,38,39]$.

Several studies have investigated correlations between respondents' attitudes to participating in research with certain demographic variables, particularly sex [40], ethnicity [41] and level of education [31]. Our study has shown some interesting and often significant correlations between attitudes towards various types of dental research and several of the studied demographic factors.

We recognize several limitations to our study. First, our sample was recruited based on convenience sampling and hence the views of participants who completed the survey might not reflect those of the general Jordanian population. Secondly, our sample was limited to those who agreed to participate in a survey study and hence it is possible that those who rejected participation would have different insights regarding participation in research. Finally, the generalizability of our findings may also be limited because only participants who were literate were selected to participate, as the survey tool was self-administered. However, more than $92 \%$ of the Jordanian population are literate [16] and therefore this aspect of our research design might not be of consequence.

Nevertheless, this study gives a comprehensive view of Jordanian patients' motives and concerns with regards to participating in dental research as research subjects. In the past, advances in dentistry were mostly innovations in dental materials, dental equipment and diagnostic aids. While these innovations have revolutionized the practice of dentistry [42], prevention and alleviation of various oral and dental diseases requires future research involving human subjects and human tissues. Having said this, by comparison with the medical and pharmaceutical industry, research in dentistry probably poses less risk to research subjects, because it frequently involves in vitro research (on extracted teeth) or in vivo topical applications, both of which have little systemic involvement. Accordingly, investigators might think that such minimal risk research might not need a rigorous regulatory framework. However, as shown in this study, dental patients have explicit opinions regarding dental research, even research that incorporates minimal risk procedures. To maintain and further 
enhance the trust of dental patients in the research endeavour, more studies are needed to explore their attitudes towards participation in research.
Acknowledgements

Funding: We acknowledge Fogarty International Center at the National
Institutes of Health, United States of America, grant no. R25TW007090, for supporting this research.

Competing interests: None declared.

\section{References}

1. Normile D. The promise and pitfalls of clinical trials overseas. Science, 2008, 322:214-216.

2. ClnicalTrials.gov. US National Institutes of Health [Internet] (www.clinicaltrials.gov, accessed 22 November 2013).

3. Adams J et al. Global research report, Middle East. Exploring the changing landscape of Arabian, Persian and Turkish research. Leeds, United Kingdom, Thomson Reuters, 2011 (http://www. tumj.ir/pdf/globalresearchreport.pdf, accessed 22 November 2013).

4. Declaration of Helsinki. Ethical principles for medical research involving human subjects. Ferney-Voltaire, France, World Medical Association. 2008. (http://www.wma.net/ en/30publications/10policies/b3/index.html, accessed 22 November 2013).

5. International ethical guidelines for biomedical research involving human subjects. Geneva, Council for International Organizations of Medical Sciences, 2002.

6. Ramahi I, Silverman H. Clinical research law in Jordan: an ethical analysis. Developing World Bioethics, 2009, 9:26-33.

7. Sugarman $\mathrm{J}$ et al. What patients say about medical research. IRB, 1998, 20:1-7.

8. Madsen SM et al. Attitudes towards clinical research amongst participants and nonparticipants. Journal of Internal Medicine, 2002, 251:156-168.

9. Ellis PM, Butow PN. Focus group interviews examining attitudes to randomised trials among breast cancer patients and the general community. Australian and New Zealand Journal of Public Health, 1998, 22:528-531.

10. Asai A et al. Focus group interviews examining attitudes toward medical research among the Japanese: a qualitative study. Bioethics, 2004, 18:448-470.

11. Farmer DF et al. Attitudes of African American and low socioeconomic status white women toward medical research. Journal of Health Care for the Poor and Underserved, 2007, 18:85-99.

12. Khalil SS et al. Attitudes, understanding, and concerns regarding medical research amongst Egyptians: a qualitative pilot study. BMCMedical Ethics, 2007, 8:9.

13. Nabulsi M, Khalil Y, Makhoul J. Parental attitudes towards and perceptions of their children's participation in clinical research: a developing-country perspective. Journal ofMedical Ethics, 2011, 37:420-423.

14. Al-Qadire MM et al. Saudi views on consenting for research on medical records and leftover tissue samples. BMC Medical Ethics, 2010, 11:18.

15. Gillett GR. Ethics and dental research. Journal of Dental Research, 1994, 73:1766-1772.

16. Jordan figures. Amman, Jordan, Department of Statistics, 2008 (http://www.dos.gov.jo/dos_home_a/main/jorfig/2008/ jor_f_a.htm, accessed 22 November 2013).

17. Wendler D et al.; ESPRIT Group. Why patients continue to participate in clinical research. Archives of Internal Medicine, 2008, 168:1294-1299.

18. Udrea G et al. Patients' perspectives and motivators to participate in clinical trials with novel therapies for rheumatoid arthritis. Journal of Medicine and Life, 2009, 2:227-231.
19. Wang LH et al. Intention, needs, and expectations of cancer patients participating in clinical trials. Cancer Nursing, 2011, 34:117-123.

20. Lowton K. Trials and tribulations: understanding motivations for clinical research participation amongst adults with cystic fibrosis. Social Science and Medicine, 2005, 61:1854-1865.

21. Kass NE, Maman S, Atkinson J. Motivations, understanding, and voluntariness in international randomized trials. IRB, 2005, 27:1-8.

22. Macklin R. On paying money to research subjects: 'due' and 'undue' inducements. IRB, 1981, 3:1-6.

23. Lind SE. Dilemmas in paying for clinical research: the view from the IRB. IRB, 1987, 9:1-5.

24. Grady C. Money for research participation: does in jeopardize informed consent? American Journal of Biology, 2001, 1:40-44.

25. Halpern SD et al. Empirical assessment of whether moderate payments are undue or unjust inducements for participation in clinical trials. Archives of Internal Medicine, 2004, 164:801-803.

26. Kass NE et al. Balancing justice and autonomy in clinical research with healthy volunteers. Clinical Pharmacology and Therapeutics, 2007, 82:219-227.

27. Hussain-Gambles M. South Asian patients' views and experiences of clinical trial participation. Family Practice, 2004, 21:636-642.

28. Ellis PM et al. Attitudes to randomized clinical trials amongst out-patients attending a medical oncology clinic. Health Expectations, 1999, 2:33-43.

29. Cassileth BR et al. Attitudes toward clinical trials among patients and the public. Journal of the American Medical Association, 1982, 248:968-970.

30. Welton $\mathrm{AJ}$ et al. Is recruitment more difficult with a placebo arm in randomised controlled trials? A quasirandomised, interview based study. British Medical Journal, 1999, 318:11141117.

31. Awad MA et al. Determinants of patients' treatment preferences in a clinical trial. Community Dentistry and Oral Epidemiology, 2000, 28:119-125.

32. Appelbaum PS et al. False hopes and best data: consent to research and the therapeutic misconception. Hastings Center Report, 1987, 17:20-24.

33. Miller FG, Rosenstein DL. The therapeutic orientation to clinical trials. New England Journal of Medicine, 2003, 348:13831386.

34. Wazaify M, Khalil SS, Silverman HJ. Expression of therapeutic misconception amongst Egyptians: a qualitative pilot study. BMC Medical Ethics, 2009, 10:7. doi.org/10.1186/1472-693910-7.

35. Robinson EJ et al. Lay public's understanding of equipoise and randomisation in randomised controlled trials. Health Technology Assessment, 2005, 9:1-192.

36. Leach $\mathrm{A}$ et al. An evaluation of the informed consent procedure used during a trial of a Haemophilus influenzae type B conjugate vaccine undertaken in The Gambia, West Africa. Social Science and Medicine, 1999, 48:139-148. 
37. Jafarey A. Informed consent: views from Karachi. Eastern Mediterranean Health Journal, 2006, 12(Suppl. 1):S50-S55.

38. Kass NE et al. Trust, the fragile foundation of contemporary biomedical research. Hastings Center Report, 1996, 26:25-29.

39. Shah JY et al. What leads Indians to participate in clinical trials? A meta-analysis of qualitative studies. PLOS ONE, 2010, 5:e10730.

40. Ding EL et al. Sex differences in perceived risks, distrust, and willingness to participate in clinical trials: a randomized study of cardiovascular prevention trials. Archives of Internal Medicine, 2007, 167:905-912.
41. Shavers VL, Lynch CF, Burmeister LF. Knowledge of the Tuskegee study and its impact on the willingness to participate in medical research studies. Journal of the National Medical Association, 2000, 92:563-572.

42. Rossomando EF. Innovation in dental practice in the decade 2000 to 2010: a confluence of science, politics, and social change. Compendium of Continuing Education in Dentistry, 2010, 31:102-103. 